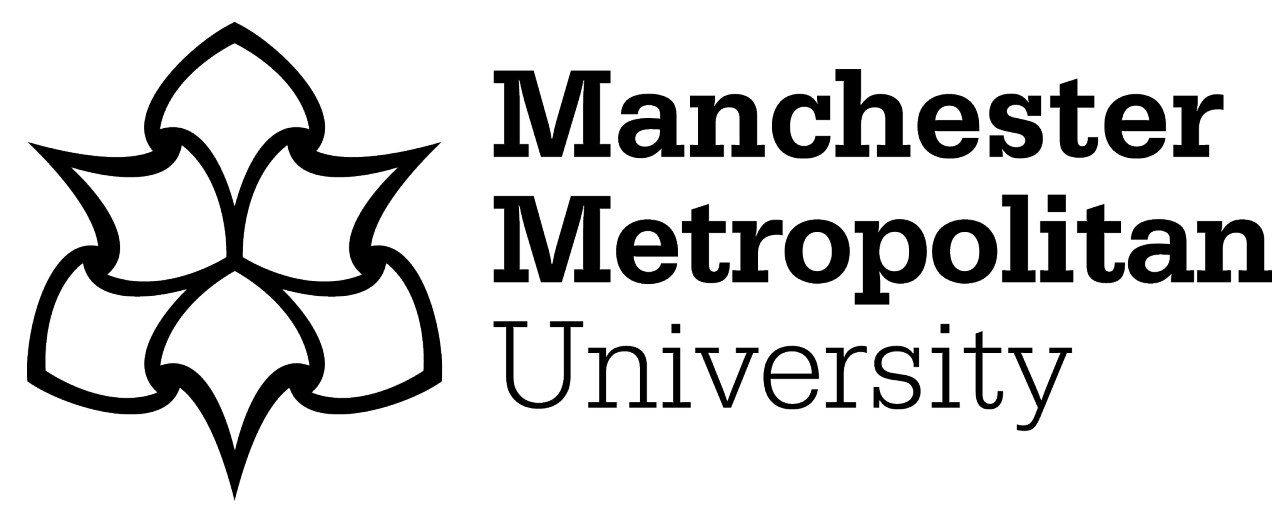

Van Hout, MC, Al-Afifi, MF, Abushams, L, Kewley, S, Quigg, Z, Whitfield, M, McVeigh, J ORCID logoORCID: https://orcid.org/0000-0001-5319-6885 and Wazaify, M (2020) Palestinian children's experiences of drug abuse in the home in the Occupied Territories of Palestine: a scoping review of extant literature. International Journal of Mental Health and Addiction, 18 (6). pp. 1572-1585. ISSN 1557-1874

Downloaded from: https: //e-space.mmu.ac.uk/624843/

Version: Accepted Version

Publisher: Springer Verlag

DOI: https://doi.org/10.1007/s11469-019-00085-2

Please cite the published version 


\section{International Journal of Mental Health and Addiction Palestinian children's experiences of drug abuse in the home in the Occupied Territories of Palestine: A scoping review of extant literature --Manuscript Draft--}

Manuscript Number:

Full Title:

Article Type:

Keywords:

Corresponding Author:
IJMH-D-19-00071R1

Palestinian children's experiences of drug abuse in the home in the Occupied Territories of Palestine: A scoping review of extant literature

Regular Article

Alcohol, Children; Drugs; Gaza; Jerusalem; Palestine; Parents; Siblings; substance abuse; West Bank

Mayyada Wazaify

University of Jordan

Amman, JORDAN

Corresponding Author Secondary Information:

Corresponding Author's Institution:

University of Jordan

\section{Corresponding Author's Secondary} Institution:

First Author: Marie Claire Van Hout

First Author Secondary Information:

Order of Authors:

Marie Claire Van Hout

Mohammed Fathi Al-Afifi

Leen Abushams

Stephanie Kewley

Zara Quigg

Mark Whitfield

Jim McVeigh

Mayyada Wazaify

Order of Authors Secondary Information:

Funding Information:

Liverpool John Moores University

(The Global Challenges Research Fund

Prof. Marie Claire Van Hout

(GCRF) Small Grants Scheme 2019)

\section{Abstract:}

The Occupied Territories of Palestine (OtP) consists of the non-contiguous West Bank including East Jerusalem, and the Gaza Strip. Its dense population with political and economic tensions is affected by a rise in drug trafficking, abuse and addiction. A scoping review mapped what is known about Palestinian children's experiences of drug abuse in the home. Following application of exclusion measures, six records remained. Charting and analysis resulted in three themes; The consequences of being a child with a drug using parent; Causal factors of drug use in Palestinian families; and Prevalence rates of parental drug use are unknown. The review paints a concerning picture of stigma, family dysfunction, school drop-out, child and family isolation and maladaptive child development. Exposure to drugs, trauma and abuse contributes to strong potential for Palestinian child drug use, sexual exploitation, overdose, psychiatric illness, and infectious diseases acquisition. The review will inform the urgent strategic response.

Response to Reviewers:

Thanks for your time and effort in reviewing our paper and the positive feeedback you had proovided.

There was only one request to address, and that was to add a "Limitations" section 
which we did.

Regards,

Powered by Editorial Manager ${ }^{\circledR}$ and ProduXion Manager ${ }^{\circledR}$ from Aries Systems Corporation 
1 Palestinian children's experiences of drug abuse in the home in the Occupied

2 Territories of Palestine: A scoping review of extant literature

3 Author Listing:

4 Marie Claire Van Hout, Professor, Public Health Institute (PHI), Liverpool John Moores

5 University, Liverpool, United Kingdom

6 Mohammed Fathi Al-Afifi, Director, Substance Abuse Research Centre (SARC), Gaza Strip

7 Leen Abushams, Researcher, School of Pharmacy, University of Jordan, Amman, Jordan.

8 Stephanie Kewley, Senior Lecturer Forensic Psychology, School of Science, Liverpool John

9 Moores University, Liverpool, United Kingdom.

10 Zara Quigg, Reader of Behavioural Epidemiology, Public Health Institute (PHI), Liverpool John

11 Moores University, Liverpool, United Kingdom

12 Mark Whitfield, Intelligence and Surveillance Manager, Public Health Institute (PHI), Liverpool

13 John Moores University, Liverpool, United Kingdom.

14 Jim McVeigh, Director, Public Health Institute (PHI), Liverpool John Moores University,

15 Liverpool, United Kingdom

16 Mayyada Wazaify, PhD, Professor of Pharmacy, Department of Biopharmaceutics and Clinical

17 Pharmacy, School of Pharmacy, The University of Jordan (UJ), Amman, Jordan

18 Address for correspondence and reprints:

19 Professor Mayyada Wazaify

20 Department of Biopharmaceutics and Clinical Pharmacy 
21 School of Pharmacy - University of Jordan

22 Amman - Jordan

23 Email: m.wazaify@ju.edu.jo

24 Fax: +9626-5300250

25 Telephone: +9626-5355000 (ext.23354)

26 
1 Palestinian children's experiences of drug abuse in the home in the Occupied Territories of Palestine: A scoping review of extant literature

4 The Occupied Territories of Palestine (OtP) consists of the non-contiguous West Bank including

5 East Jerusalem, and the Gaza Strip. Its dense population with political and economic tensions is

6 affected by a rise in drug trafficking, abuse and addiction. A scoping review mapped what is known

7 about Palestinian children's experiences of drug abuse in the home. Following application of

8 exclusion measures, six records remained. Charting and analysis resulted in three themes; The

9 consequences of being a child with a drug using parent; Causal factors of drug use in Palestinian

10 families; and Prevalence rates of parental drug use are unknown. The review paints a concerning

11 picture of stigma, family dysfunction, school drop-out, child and family isolation and maladaptive

12 child development. Exposure to drugs, trauma and abuse contributes to strong potential for

13 Palestinian child drug use, sexual exploitation, overdose, psychiatric illness, and infectious

14 diseases acquisition. The review will inform the urgent strategic response.

15 Key Words

16 Alcohol, Children, Drugs, Gaza, Jerusalem, Palestine, Parents, Siblings, Substance Abuse, West 17 Bank

\section{Background}

The Occupied Territories of Palestine (OtP) consists of the non-contiguous West Bank including

21 East Jerusalem, and the Gaza Strip. It is densely populated within these confines, and has a unique 
socio-economic context characterized by political and economic tensions. Approximately five million Palestinians live in the OtP (about 2 million in Gaza with $66.2 \%$ refugees living in eight camps, and about 3 million in the West Bank and Jerusalem with 26.6\% refugees living in 19 camps). Palestinians are also displaced into neighbouring Jordan where there are about 2,175,000 registered refugees living in ten camps, into Syria with about 552,000 in nine camps, and into Lebanon with about 450,000 living in 12 camps. About $40 \%$ of these refugees are children (Waterston \& Nasser, 2017). Substance use by Palestinian youth and their families is present, despite religious, legal, and cultural constraints even in socially conservative communities, and is underpinned by stress, economic hardship, the repeated exposure to political violence and the Israeli occupation, school closures and travel restrictions (Massad et al., 2016). These conditions have facilitated a rise in drug trafficking, drug abuse and addiction amongst Palestinian communities, with increasing prevalence of illicit, over the counter (OTC) and prescription drug use observed among young Palestinians, Palestinian women and family members of current drug users (Palestinian National Institute of Public Health,2017b; Palestinian National Institute of Public Health,2017a; Damiri et al., 2018b). Abuse of OTC drugs has been reported in Palestine since 2004 (Sweileh et al., 2004) as well as proportionately high rates of cigarette smoking amongst young Palestinians (Jawad et al., 2016). Most recent situational assessments conducted in 2017 have reported that drug trends include marijuana, prescription medications (antidepressants, Z-hypnotics, benzodiazepines and analgesics), and novel psychoactive substances (NPS) ('Sintetique Marijuana'), with reported high dose use of methadone, morphine, phencyclidine, barbiturates, benzodiazepines, synthetic opioids such as tramadol, and gabapentinoid drugs such as Pregabalin (Palestinian National Institute of Public Health, 2017a). Damiri et al., reported in 2018, on the rise since 2013 of trafficking and use of NPS, particularly 
synthetic cannabinoids, the manufacture of liquid amphetamine, and the cultivation of marijuana in the OtP (B. Damiri et al., 2018b). Most recent estimations in 2018 indicate that there are now over 80,000 drug users in the OtP. There are now an estimated 26,500 high-risk drug users (HDU) in Palestine, consisting of $1.8 \%$ of the male population aged over 15 years, with over $80 \%$ reporting use before the age of 17 years, and of which $4.2 \%$ report injecting use of heroin or cocaine (Palestinian National Institute of Public Health, 2017a). Risk behaviours are higher among males, older youth, in urban areas and refugee camps (Thabet \& Dajani, 2012; Glick et al., 2018). Most HDUs live in the north and south of the West Bank, and Gaza. Prevalence of hepatitis C (and human immunodeficiency virus, HIV to a lesser extent) has increased and is associated with sharing of needles and other equipment between the injectors of heroin and cocaine (Palestinian National Institute of Public Health, 2017a). Factors contributing to such high risk behaviours in addition to easy access to alcohol and drugs, centre on poor social services, social and political tensions, and inability of the Palestinian law enforcement to police the influx of drugs into the West Bank, East Jerusalem and Gaza (Massad et al., 2016). There is also a widespread held belief among Palestinians that Israel makes little effort to deter the supply of drugs into the OtP, and this facilitates the spread of substance abuse among the Palestinian people, especially youth in order to destroy their future (Massad et al., 2016). Most recently in 2019, the Palestinian Ministry of Health with technical support from the United Nations Office on Drugs and Crime Programme Office in the OtP (UNODC-POPSE) has responded to the problem of drug dependence and HIV and has established the Palestinian National Rehabilitation Centre (United Nations Office for Drugs and Crime (UNODC), 2019). Occupation by the Israeli state is a significant determinant of Palestinian children's' health situation (Giacaman et al., 2009; Horton, 2009). Very little is known 67 about Palestinian children's' experiences of substance abuse in the home, and the related impacts, 
with Massad et al., 2016 underscoring the need to further understand and respond (Massad et al.,

2016). There has been little research on or indeed response to Palestinian children's unique and urgent needs relating to trauma and vulnerabilities caused by drug abuse in the home. Their situation is exacerbated by the hidden nature of drug abuse within their families. Hence a scoping review was undertaken to map and describe what is known about Palestinian children's experiences of sibling and parental drug abuse.

Methods

Scoping reviews are defined by Tricco et al. in 2016 (2016) as "a type of knowledge synthesis, 77 follow a systematic approach to map evidence on a topic and identify main concepts, theories, sources, and knowledge gaps." They are an independent research methodology proposed by Arksey and O’Malley (Arksey \& O’Malley, 2005) and further advanced by Levac et al. (2010) and others (Peters et al., 2015; Khalil et al., 2016). Scoping reviews address broader questions than systematic reviews and are usually conducted to identify gaps in knowledge, examine the extent

82 (i.e.- size), range (i.e.- variety), and nature (i.e.-characteristics) of the evidence on a certain topic or question; summarize findings from a body of knowledge that is heterogeneous in methods or 84 discipline; or set agendas for future research (Tricco et al., 2016). The review adopted the five stage scoping review method as developed by Arskey and O’Malley (Arksey \& O’Malley, 2005). These stages included: (1) identifying the essential research question, (2) searching for similar 87 studies, (3) study selection, (4) charting the data, and (5) collecting, summarizing, and recording the results. The research team identified the underpinning research question (What do we know 89 about Palestinian children's experience of alcohol or drug abuse at home?) and reviewed all 90 available published literature on this topic. A mapping exercise was conducted and included all 
91 published studies of Palestinian children (under 18 years of age) of both genders, with no date or

92 methodological restriction. To enable the broadest picture of current knowledge and perceptions

93 relating to the issue of Palestinian children's' experiences of substance abuse in the home, we

94 included international and national policy documents and reports, academic theses, online reports,

95 conference proceedings, commentary pieces and editorials, in addition to articles in scholarly peer

96 reviewed journals. The search was implemented in January 2019 in the University of Jordan and

97 Liverpool John Moores University Library catalogues, using the following databases: Science

98 Direct, Electronic Library of Medicine, Hinari, Google Scholar, Cochrane Library, and PubMed.

99 A thorough list of search terms was compiled by the team who had pharmacy, public health,

100 addiction, forensic science and clinical specialisms. The search combined the terms "Palestine"

101 OR “West Bank” OR “Gaza” with “abuse," "misuse,” "dependence,”, “addiction”, “alcohol”,

102 “drugs", “substance use”, “children”, “youth” and "adolescents”.

103

104 Four researchers screened literature titles and abstracts to determine their inclusion status. Full text

105 articles were reviewed and screened by four additional independent researchers to ensure that they

106 met the inclusion criteria. Full text articles were compiled in a shared file by the author, year, and

107 title of the study to avoid duplication. References were managed by the citation manager Endnote ${ }^{\circledR}$.

108 This software promoted the recording and organization of all related literature. This allowed cross-

109 monitoring of data records, removal of duplicates, and extraction of information from the papers

110 contained in the review. Follow-up search strategies included website searches of international aid,

111 human rights and development organisations, health, medical and human rights-related databases,

112 websites of Palestinian government and non-governmental organisations (NGOs) and

113 investigative news reports. Reference lists in reports, investigative news articles, journal papers 
114 and academic theses were also manually searched by the team to identify any additional relevant 115 literature not captured. The disagreements of the relevance of data were resolved through 116 discussion.

The initial search identified 1,397 articles, with no duplicates. After the exclusion of articles where full text was not available, and lack of relevance specifically to Palestine or alcohol or drug abuse; a total of 6 records were identified to directly relate to the experience of Palestinian children's exposure to alcohol or drug abuse at home. (Figure 1). The six records were charted and thematically analysed, as per Levac et al (2010).

\section{Insert Figure. 1 about here}

This process of documentation and analysis of information generated specific themes pertaining to Palestinian children's experiences of parental or sibling substance use and abuse in the home.

128 A spreadsheet was created to chart relevant data (data collection categories, year of publication, 129 author, location, method and aim, key findings and conclusion) and identify commonalities, 130 themes, and gaps in the literature. A trial charting exercise of several records was conducted by 131 the team as recommended by Daudt et al. (2013), followed by a joint consultation to ensure 132 consistency with the research question and the purpose of the scoping review. Based on this 133 preliminary exercise, the team developed prior categories which guided the subsequent extraction 134 and charting of the data from the records. All records were charted and analysed by four reviewers 135 in consultation, with disagreements around theme allocation resolved through discussion. Where 
136 additional data extraction categories emerged, consultation guided decisions around allocation and

137 reporting.

139 Results

140 In our examination of the extant literature we found six articles documenting Palestinian

141 children's experiences of alcohol or drug abuse in the home. Table 1 summarises each of these

142 documents; two of which are media articles, two are studies from the Defence for Children

143 International (a not for profit organisation campaigning for children's rights across the world);

144 one study by the Palestinian National Institute of Public Health (and UNODC/KOICA/WHO);

145 and one peer reviewed academic study.

146

147

Insert Table 1 about here

148

149 In collecting, summarising, charting and analysing the results of the search, three themes

150 emerged. These include: 'The consequences of being a child with a drug using parent'; 'Causal

151 factors of drug use in Palestinian families'; and 'Prevalence rates of parental drug use are

152 unknown'.

153

154 Theme One: The consequences of being a child with a drug using parent

155 Across the whole sample of records, this underpinning theme was by far the most frequently

156 discussed.

157 Addiction in children/subsequent criminalisation 
158 One of the consequences of children living with addicted parents (or family members) is the 159 increased likelihood that they themselves become addicted to drugs and alcohol. A combination 160 of ease of access, normalisation, and a means of escape were cited in three of the six papers 161 (Defence for Children International/Palestine Section, 2006; Palestinian National Institute of 162 Public Health, 2017b; Damiri et al., 2018a) as reasons why Palestinian children of addicted parents 163 themselves begin to use drugs. Access to drugs, alcohol, and tobacco are reported as being readily 164 available through a range of sources, one of which is access in the home (Damiri et al., 2018a). 165 Palestinian children with an ease of access to illicit substances are themselves more vulnerable to 166 future addiction and behavioural issues. The consequences of being a child with a drug using parent 167 are discussed here, but it is worth noting that the psychological, social, and health consequences 168 to a Palestinian child using drugs and alcohol during the early developmental stages of 169 adolescence, are substantial. Drug taking at a young age can have long-lasting effects on the 170 person's psychological and social functioning.

171 Stigma

172 The stigma of addiction across the OtP is significant. One aspect of this social construction is that 173 the stigma spreads beyond the addict themselves, branding their family members with the same 174 label (Palestinian National Institute of Public Health, 2017b; Damiri et al., 2018a). The 175 consequences for Palestinian children of addicted parents are, therefore, important to note because 176 within their community, they too become marked and rejected. The result of such stigma causes 177 not only a breakdown within families of addicted parents, but also amongst children's wider 178 friendships circles. Without access to developing healthy supportive non-drug using relationships, 179 these Palestinian children lack the opportunities provided by social and support networks, such as 180 increasing social capital, as well as having their developmental skills compromised. 
182 While not explicitly connected to parental addiction, studies in this review indicate problems 183 experienced by children accessing and continuing with their education as a result of problems within the home. In one study "children in the street" completed questionnaires exploring how and why children as young as five years old in Palestine were living and working out on the streets (Ramahi, 2014). One of the contributing factors to children dropping out of education was that they were needed to financially support their family. This was a result of at least one parent being addicted to drugs or alcohol and therefore, unemployed, and unable to support the family. In another report (Palestinian National Institute of Public Health, 2017b) (that does not overtly highlight the educational problems within these children), it highlights that Palestinian children running away from home do so to protect themselves from drug using fathers, it is likely to assume these children also drop out of education.

Neglect, malnutrition, disease, and physical violence

194 In half of the studies included in this review attention is given to the harms experienced by 195 children of addicted parents (Ramahi, 2014; Palestinian National Institute of Public Health, 2017b; Shani, 2017). Children living and working out on the street report the physical conditions in which they are required to work, these often result in having to work in extremely cold or very hot conditions, often for long periods of time, without adequate food and water. These children are exposed to physical violence from several sources including other children competing for work; officials such as law enforcement; and passers-by who target these children's vulnerability. Likewise, drug addicted parents are more likely to contribute to spreading infectious diseases and sexually transmitted infections within their family (Defense for Children International/Palestine Section, 2007), and as such, children living and caring for family members in 
these conditions, are more susceptible to disease. Around $90 \%$ of the counsellors interviewed in one study (Defense for Children International/Palestine Section, 2006) reported that addicted parents are responsible for the physical harms and assaults inflicted on their children.

207 Sexual abuse

208 Four of the six studies reported a growing concern of sexual abuse on children of addicted parents 209 (Ramahi, 2014; Defense for Children International/Palestine Section, 2006; Palestinian National Institute of Public Health, 2017b; Shani, 2017). Sexual abuse of these children occurs both within and outside of the family home. In some cases Palestinian children who are out working on the 212 street, runaway to escape their abuser (Palestinian National Institute of Public Health, 2017b) or 213 are forced into the sex trade (Defense for Children International/Palestine Section, 2006) and thus, 214 experience sexual abuse by people outside of the family. These children are unprotected by 215 authorities as many of the abusers include law enforcement themselves, or if children are arrested 216 (perhaps for their own drug use) they are incarcerated and exposed to adult prisoners who perceive 217 them as defenceless targets; as a result, they are further sexually exploited. Palestinian children 218 also face an increased risk of sexual abuse by a family member when at least one parent is addicted 219 to drugs (Shani, 2017). Abuse may be perpetrated by the addicted parent, or the child's brothers 220 or uncles within the family. One report included the issue of the silence and lack of action from 221 child protection services in the OtP. It noted how the abuse and trauma experienced by children 222 living in these conditions is ignored by professional services. A final area identified by Palestinian 223 children who are sexually abused as a result of living in an addicted household, is that they 224 themselves are more vulnerable to becoming perpetrators of sexual abuse to other children. It is 225 thought that these children learn maladaptive coping strategies and one way to self-soothe their 226 trauma is to seek sexual intimacy from other children. 
229 A final consequence identified in three of the six studies (Ramahi, 2014; Defense for Children 230 International/Palestine Section, 2007; Shani, 2017) is the significant breakdown of family and 231 social bonds. Children of addicted parents in the OtP experience fractured family units, this 232 fracturing impacts on the ability of children to develop close social relationships as children but 233 also meaningful and strong relationships as adults. The development needs of children are such 234 that they require a family environment that is nurturing, loving, and safe; they require the 235 development of secure parental attachments, from which the child learns how to develop healthy 236 relationships with others. Given the political and socio-economic situation in the OtP, this is even 237 more important. Where Palestinian children become the main source of economic stability in the 238 family (perhaps because they are set out to work (Ramahi, 2014; Defense for Children 239 International/Palestine Section, 2007) rather than attend school and have opportunities to play) 240 they inevitably fail to develop friendships and bonds with others their own age. Not having the 241 capacity to develop healthy functioning relationships, result in these Palestinian children 242 developing dysfunctional relationships and maladaptive and even harmful strategies (such as drug 243 use, sexually abusing others, and prostitution) to cope.

244 Theme Two: Causal factors of drug use in Palestinian families

245 Political and socio-economic context

246 All six sources document the continuing political and economic tensions that have "created 247 conditions that facilitate the spread of illicit drug use” (Palestinian National Institute of Public 248 Health, 2017b, p. 9). This review finds Palestinians homeless, without work, having to live in 249 restricted zones and areas, often facing political violence and threats, resulting in an environment 
250 of disorder and chaos. One solution some Palestinians use to survive and cope, is to self-medicate 251 using illegal drugs and alcohol. It is reported that the use of such substances helps them relax, 252 sleep, and escape life's problems (Palestinian National Institute of Public Health, 2017b). The 253 daily conflict and struggle in which Palestinians exist, cannot be underestimated or ignored when 254 understanding some of the factors that contribute to Palestinian family members use of drugs, even 255 when they have the responsibility to care for children.

256 Stigma associated with drug use results in a lack of early treatment and prevention

257 In addition to the political and socio-economic strain in the OtP, there exists a social construction 258 that condemns drug addicts and drug use. Findings in this review ought to be considered an under 259 estimation of the prevalence of the issue, as self-reports are likely to be subject to some bias. The 260 condemnation of drug addiction and drug use is so strong in the OtP, particularly against child

261 drug addiction, that the community response is often one of rejection, verbal, physical, and sexual 262 assaults (Damiri et al., 2018a). While the stigma is projected onto individuals, it often resonates to 263 those associated with the addict. Therefore, Palestinian children whose parents are drug addicts 264 are likely to be stigmatised. This results in children being rejected by friends, future partners, and 265 future employers (Palestinian National Institute of Public Health, 2017b). A further consequence 266 of the social stigma around drug addiction, is that it prevents users seeking help and support.

267 People fear being exposed as a drug user, and Palestinian women, due to cultural expectations lack 268 the opportunity and appropriate treatment to support their needs. As a result, drug use within the 269 Palestinian family is kept hidden, help is not sought, thus, the problem continues, and sometimes 270 through to the next generation.

271 Legal system or authorities ignoring the problem 
272 A final sub-theme that enables the continuation of drug use and abuse within the home is the lack

273 of interest by law enforcement agents to tackle drug dealers within the area. In one report (Ramahi,

274 2014) drug dealers appear free to sell illegal substances to Palestinian communities; the author

275 claims that local law enforcement is unconcerned because end users are Palestinians. Likewise,

276 child protection agencies, it is alleged (Shani, 2017) are aware of cases where Palestinian children

277 are sexually abused by their fathers and brothers, but do not act to protect children because the law

278 requires the victim to prove the assault took place. Hence, Palestinian children caught up in the

279 criminal justice system, find themselves vulnerable to assaults, with reports of young people being

280 sexually and physically assaulted by law enforcement officials, or adult prisoners while in jail

281 (Ramahi, 2014).

282 Theme Three: Prevalence rates of parental drug use are unknown

283 Sources in this review indicate a clear problem with drug addiction in the OtP. Drug use amongst

284 young Palestinians is a significant concern as young people between the ages of 14 and 25 years

285 are at greatest risk of drug abuse and addiction (Defense for Children International/Palestine

286 Section, 2007). The detailed 2017 survey of the prevalence and nature of drug use amongst

287 Palestinians in the OtP provides an important picture regarding the issues for young people and

288 drug abuse in this area (Palestinian National Institute of Public Health, 2017b). Studies included

289 in this review however, do not provide prevalence rates of drug using parents and the numbers of

290 children they are responsible for. Studies report the detrimental consequences of parents using

291 drugs, for example, there has been an observed increase in violence (Defense for Children

292 International/Palestine Section, 2006), sexual abuse (Shani, 2017), poverty (Defense for Children

293 International/Palestine Section, 2007) and childhood addiction (Damiri et al., 2018), yet it remains

294 unknown how prevalent parental drug use is and how many Palestinian children are affected. 
295 While the findings from media sources and NGO reports cannot be underestimated nor ignored, 296 they do not stand up to the rigours and critique of empirical research.

\section{Discussion}

299 We have presented here the first known mapping exercise on extant literature on the issue of 300 Palestinian children affected by familial, parental or sibling drug abuse in the home in the OtP. 301 This work builds on the recent increase in research and surveillance activity on drug abuse in the 302 OtP (Palestinian National Institute of Public Health, 2017b; Palestinian National Institute of Public 303 Health, 2017a; Damiri et al., 2018a; United Nations Office for Drugs and Crime (UNODC), 2019; 304 Thabet \& Dajani, 2012; Glick et al., 2018; Massad et al., 2016). Whilst our review is small-scale, 305 the analysis of records reveals a concerning picture of stigma, family dysfunction, school drop306 out, child and family isolation, risks and harms, and maladaptive child development experienced 307 by Palestinian children affected by drug abuse in their homes. Exposure to drugs, trauma and a myriad of abuse (physical, emotional and sexual) contribute to a high risk of Palestinian child and 309 youth drug use, sexual exploitation, overdose and witnessing of overdose, psychiatric illness, and infectious diseases acquisition. The review is intended to inform a timely strategic response to the needs of Palestinian children exposed to drug abuse by family members in the home.

313 Štulhofer et al. in (2012) have underscored how present and worsening conditions relating to the 314 Israeli military occupation of Palestine are likely to generate conditions conducive to drug abuse 315 and addiction. This recent and continuing rise in drug availability and drug abuse has severe social, psychological, economic and health impacts on Palestinian communities, and most

317 particularly children and young people (United Nations Office for Drugs and Crime (UNODC), 
2019). Studies in recent times have underscored the grave situation for Palestinian children in terms of malnutrition, mental health issues, exposure to violence and discrimination, accidents, violation of children's rights, and barriers to access and restricted access to healthcare, particularly in Gaza which is experiencing a health crisis, checkpoints for ambulance transit, requirements for permits to travel into Jerusalem for specialised care, weak health infrastructure and medical training, and medicines shortages and off label use (Waterston \& Nasser, 2017; Khdour et al., 2011). There is evidence of an association between Palestinian children's experiences of political and community level violence and poor mental health (depression, anxiety and hopelessness), post-traumatic stress disorder (PTSD), stress and externalising symptoms including violent aggression (Abdeen et al., 2008; Garbarino \& Kostelny, 1996; Sharek Youth Forum, 2008; Giacaman et al., 2011).

Our review further highlights Palestinian children's compounded situation if affected by parental drug abuse in the home. Stigma of addiction in Arab society is significant, with drug abuse in the home causing family breakdown and dysfunction, community rejection of whole family units, a multiplicity of adverse childhood experiences (ACES) for those children affected, educational drop out of children in order to care and financially provide for the family, and with resultant severe isolation of these children from their wider social and friendship networks ( Damiri et al., 2018a). Overall this destructive effect creates isolation, experience of wide ranging traumas and unsafe living environments, and results in maladaptive child coping measures and even harmful strategies (such as drug use, sexually abusing others, and prostitution (Defense for Children International/Palestine Section, 2006; Shani, 2017; Defense for Children International/Palestine Section, 2007; (Damiri et al., 2018a). Equally concerning is the underlying inferred prevalence 
341 and risk of child sexual abuse and exploitation by family members and the lack of law enforcement

342 response to sexual abuse and indeed drug trafficking in the OtP (Ramahi, 2014; Defense for 343 Children International/Palestine Section, 2006; Palestinian National Institute of Public Health, 344 2017b; Shani, 2017). Hence, there is strong potential for drug exposed and traumatised Palestinian 345 children to use drugs themselves, become dependent and with risk of overdose, psychiatric events, 346 and infectious disease (HIV, Hepatitis C, and sexual transmitted infection) acquisition (Palestinian 347 National Institute of Public Health, 2017b; Palestinian National Institute of Public Health, 2017a; 348 Damiri et al., 2018b; Massad et al., 2016). Of note is the commendable efforts to pilot counselling 349 and parenting programmes in Palestine in order to reduce childhood trauma, improving levels of 350 self-awareness and reducing PTSD symptoms for children experiencing symptoms of trauma and 351 support parenting skills among Palestinians affected by considerable stress, and serious illness as 352 consequence of unsafe drug injection and sexual activity (Murphy, 2016; Mahamid et al., 2015). 353 Lastly we recognise the unique vulnerabilities of Palestinian women in the home, alongside their 354 stigmatisation if affected by drug abuse, or engaging in drug abuse themselves.

\section{Limitations}

357 We observe the limitations of our current knowledge of Palestinian children affected by drug abuse in the 358 home based upon this small review. Despite conducting a robust search in English and Arabic, and 359 searching the grey literature in addition to peer review publications, a limitation of this scoping review is 360 the small number of records found which refer to or illustrate the complexities of children affected by 361 parental or sibling drug abuse in the home. The area is under researched. Studies included in this review 362 did not explicitly set out to capture the essence of Palestinian children's experiences living with drug using 363 parents and siblings. When exploring unknown territories and experiences that are highly sensitive, 364 subjective, covert and complex, a cross sectional questionnaire is unlikely to capture lived experience and 
meaning, particularly in children. However, by conducting detailed narrative and content analysis of

366 these records, in examining drug and alcohol use in young people in Palestine, this review has

367 managed to extract some sense of children's experiences where parents and siblings are drug users,

368 and how this impacts their mental and social states. It has further described significant and

369 concerning harms for those children concerned. Hence we recommend further investigation of the

370 issue in order to better understand the phenomenon, and to inform targeted gender specific, family

371 and addiction support measures in the OtP.

372

373 Conclusion

374 The issue of rising drug abuse in the OtP given the wider Arab Israeli conflict requires an 375 international, strategic and long-term inter-disciplinary, cross-sectoral and trauma-informed 376 community partnership approach. The impact of familial and sibling drug abuse on Palestinian 377 children is potentially significant and far reaching, notwithstanding their experience of existing 378 traumas, instability and conflict in the OtP. The prevalence of parental drug use and how many 379 Palestinian children are affected remains unknown despite media and anecdotal reporting by 380 community services. Dedicated measures are warranted to reduce risk and support vulnerable 381 children, children living in homes where familial drug abuse occurs; and children living in homes 382 where parents or siblings are in recovery. We call on the international community to support 383 increased surveillance of the issue in the OtP and implementation of dedicated law enforcement, 384 social support, mental health and community drug measures. 
387 The Global Challenges Research Fund (GCRF) Small Grants Scheme 2019,. Grant holder, 388 Professor Marie Claire Van Hout.

389

390

391 Funding Acknowledgement

392 The authors declare no conflict of interest of any kind.

393

394

395

396

397

398

399

400

401

402

403

404

405

406

407

408 References 
Abdeen, Z., Qasrawi, R., Nabil, S., \& Shaheen, M. (2008). Psychological reactions to Israeli occupation: Findings from the national study of school-based screening in Palestine. International Journal of Behavioral Development, 32(4), 290-297.

Arksey, H., \& O’Malley, L. (2005). Scoping studies: towards a methodological framework. International Journal of Social Research Methodology, 8(1), 19-32.

Damiri, B. R., Isra'A, S., \& Aghbar, M. H. (2018a). Pattern of substance use among schoolchildren in Palestine: a cross-sectional study. Egyptian Journal of Forensic Sciences, $8(1), 59$.

Damiri, B., Sayeh, W., Odeh, M., \& Musmar, H. (2018b). Drug use and possession, emerging of new psychoactive substances in the West Bank, Palestine. Egyptian Journal of Forensic Sciences, 8(1), 42.

Daudt, H. M. L., van Mossel, C., \& Scott, S. J. (2013). Enhancing the scoping study methodology: a large, inter-professional team's experience with Arksey and O'Malley's framework. BMC Medical Research Methodology, 13(1), 48.

Defense for Children International/Palestine Section. (2007). Children In Street: The Palestinian Case. Retrieved from https://arabic.dci-palestine.org/ dcipal/sites/arabic.dcipalestine.org/files/childreninthestreetarabic.pdf [last accessed on March $\left.9^{\text {th }}, 2019\right]$

Defense for Children International/Palestine Section. (2006). Trends of educational counselors on child abuse: Field study in schools of the Palestinian National Authority. Retrieved from https://arabic.dci-palestine.org/ dcipal/sites/arabic.dci-palestine.org/files/childabuse.pdf [last accessed on March $\left.11^{\text {th }}, 2019\right]$ 
Garbarino, J., \& Kostelny, K. (1996). The effects of political violence on Palestinian children's behavior problems: A risk accumulation model. Child Development, 67(1), 33-45.

Giacaman, R., Khatib, R., Shabaneh, L., Ramlawi, A., Sabri, B., Sabatinelli, G., ... Laurance, T. (2009). Health status and health services in the occupied Palestinian territory. The Lancet, 373(9666), 837-849.

Giacaman, R., Rabaia, Y., Nguyen-Gillham, V., Batniji, R., Punamäki, R.-L., \& Summerfield, D. (2011). Mental health, social distress and political oppression: The case of the occupied Palestinian territory. Global Public Health, 6(5), 547-559.

Glick, P., Al Khammash, U., Shaheen, M., Brown, R., Goutam, P., Karam, R., ... Massad, S. (2018). Health risk behaviours of Palestinian youth: findings from a representative survey. EMHJ-Eastern Mediterranean Health Journal, 24(02), 127-136.

Horton, R. (2009). The occupied Palestinian territory: peace, justice, and health. The Lancet, 373(9666), 784-788.

Jawad, M., Khader, A., \& Millett, C. (2016). Differences in tobacco smoking prevalence and frequency between adolescent Palestine refugee and non-refugee populations in Jordan, Lebanon, Syria, and the West Bank: cross-sectional analysis of the Global Youth Tobacco Survey. Conflict and Health, 10(1), 20.

Khalil, H., Peters, M., Godfrey, C. M., McInerney, P., Soares, C. B., \& Parker, D. (2016). An evidence- based approach to scoping reviews. Worldviews on Evidence-Based Nursing, 13(2), 118-123.

Khdour, M. R., Hallak, H. O., Alayasa, K. S. A., AlShahed, Q. N., Hawwa, A. F., \& McElnay, J. 
C. (2011). Extent and nature of unlicensed and off-label medicine use in hospitalised children in Palestine. International Journal of Clinical Pharmacy, 33(4), 650-655.

Levac, D., Colquhoun, H., \& O’Brien, K. K. (2010). Scoping studies: advancing the methodology. Implementation Science, 5(1), 69.

Mahamid, F. A. M., Rihani, S. T., \& Berte, D. Z. (2015). Expressive group counseling as a model for increasing self-awareness to reduce trauma symptoms experienced by children in Palestine. International Journal of Psychology and Counselling, 7(8), 112-118.

Massad, S. G., Shaheen, M., Karam, R., Brown, R., Glick, P., Linnemay, S., \& Khammash, U. (2016). Substance use among Palestinian youth in the West Bank, Palestine: a qualitative investigation. BMC Public Health, 16(1), 800.

Murphy, D. A. (2016). A parenting and self-care intervention for substance-using mothers: Promoting resilience among Israeli and Palestinian people. Mental Health and Addiction Care in the Middle East, 59-80. https://doi.org/https://doi.org/10.1007/978-3-319-415567_5

Palestinian National Institute of Public Health. (2017a). Estimating the Extent of Illicit Drug Use in Palestine. Retrieved from https://www.unodc.org/documents/middleeastandnorthafrica/Publications/Estimating_the_E xtent_of_Illicit_Drug_Use_in_Palestine.pdf [lasts accessed on March $11^{\text {th }}, 2019$ ]

Palestinian National Institute of Public Health.. (2017b). Illicit Drug Use in Palestine. Retrieved from https://www.unodc.org/documents/publications/Illicit_Drug_Use_in_Palestine.pdf [last accessed on March 11 $\left.1^{\text {th }}, 2019\right]$ 
472 Peters, M. D. J., Godfrey, C. M., Khalil, H., McInerney, P., Parker, D., \& Soares, C. B. (2015).

473 Guidance for conducting systematic scoping reviews. International Journal of Evidence$474 \quad$ Based Healthcare, 13(3), 141-146.

475 Ramahi, S. (2014). The scourge of drugs in Jerusalem. Middle East Monitor. Retrieved from 476 https://www.middleeastmonitor.com/20140125-the-scourge-of-drugs-in-jerusalem/ [last $477 \quad$ accessed on March $\left.2^{\text {nd }}, 2019\right]$

478 Shani, A. (2017). Gaza Kids Live in Hell: A Psychologist Tells of Rampant Sexual Abuse, Drugs 479 and Despair. Haaretz Newspaper. Retrieved from https://www.haaretz.com/middle-east480 481 482 483

Sharek. (2008). The youth talk. Perceptions of Palestinian youth on their living conditions. In: Sharek Youth Forum. Ramallah. Palestine

Štulhofer, A., Chetty, A., Rabie, R. A., Jwehan, I., \& Ramlawi, A. (2012). The prevalence of $\mathrm{HIV}, \mathrm{HBV}, \mathrm{HCV}$, and HIV-related risk-taking behaviors among Palestinian injecting drug users in the East Jerusalem Governorate. Journal of Urban Health, 89(4), 671-676.

Sweileh, W. M., Arafat, R. T., Al-Khyat, L. S., Al-Masri, D. M., \& Jaradat, N. A. (2004). A pilot

490 Thabet, A. A. M., \& Dajani, J. K. (2012). Substance abuse among Palestinians in the West Bank and Gaza Strip. Arab Journal of Psychological Science, 36, 76-78.

492 Tricco, A. C., Lillie, E., Zarin, W., O’Brien, K., Colquhoun, H., Kastner, M., ... Wilson, K. 
493

494

495

496

497

498

499

500

501

502

503

504

505

506

507

508

509

510

511

512

513

514

03

06

(2016). A scoping review on the conduct and reporting of scoping reviews. BMC Medical Research Methodology, 16(1), 15.

United Nations Office on Drugs and Crime (UNODC). (2019). Independent Evaluation of PSEY13. Supporting the establishment of evidence-based drug dependence treatment and rehabilitation system for the Palestine National Rehabilitation Centre. Retrieved from https://www.unodc.org/documents/evaluation/Independent_Project_Evaluations/2019/PSE Y13_Final_Independent_Project_Evaluation_Jan_2019.pdf [last accessed on March $9^{\text {th }}$, 2019]

Waterston, T., \& Nasser, D. (2017). Access to healthcare for children in Palestine. BMJ Paediatrics Open, 1(1).

04

05

07

08

09


1,388 records excluded for lack of relevance specifically to the OtP or the topic of alcohol or

Final number of records charted $\mathrm{N}=6$

9 articles screened for inclusion criteria.

$\mathbf{3}$ articles where full text were not available removed.

532 Figure. 1: Flow chart of the search strategy used during the scoping review of Palestinian 
Table 1. Summary of sources included in scoping review

\begin{tabular}{|c|c|c|c|c|c|}
\hline Authors & Title (Year) & Language & Method of Study & Summary & Findings related to Children of Addicted Parents \\
\hline $\begin{array}{l}\text { Defense for } \\
\text { Children } \\
\text { International. } \\
\text { Palestine Section }\end{array}$ & $\begin{array}{l}\text { Children in the Street. The } \\
\text { Palestinian case (2007) }\end{array}$ & English & $\begin{array}{l}\text { Cross sectional mixed } \\
\text { methods approach. } \\
\text { Interview with } \\
\text { Palestinian officials } \\
\text { and a survey of } 120 \\
\text { children under the age } \\
\text { of } 18 \text { working in the } \\
\text { streets across West } \\
\text { Bank and Gaza Strip }\end{array}$ & $\begin{array}{l}\text { Study found "street children" } \\
\text { tend not to be homeless per se } \\
\text { but their street experiences } \\
\text { includes dealing with poor } \\
\text { weather and 'work' conditions, } \\
\text { as well as, physical, } \\
\text { psychological and sexual abuse, } \\
\text { and harassment. }\end{array}$ & $\begin{array}{l}\text { It was because of a parent's addiction that contributed to } \\
\text { problems within the family, which in turn, renders Palest } \\
\text { children as a "child in street." } \\
\text { Many of these children are classified as those in most nee } \\
\text { assistance from child protection services. }\end{array}$ \\
\hline Ramahi, S & $\begin{array}{l}\text { The scourge of drugs in } \\
\text { Jerusalem (2014) }\end{array}$ & English & Media Monitoring & $\begin{array}{l}\text { The article reported on the } \\
\text { prevalence and increase in drug } \\
\text { addiction across East Jerusalem. } \\
\text { The reporter noted this issue } \\
\text { affects the family of those } \\
\text { addicted, including the stigma } \\
\text { associated with drug use, and } \\
\text { that young people between ages } \\
14-25 \text { are at greatest risk of } \\
\text { addiction. }\end{array}$ & $\begin{array}{l}\text { For children of an addicted parent the consequences are } \\
\text { significant in terms of family breakdown, economic and s } \\
\text { breakdown. The stigma associated with a family member } \\
\text { using drugs is a concern as the stigma extends beyond the } \\
\text { individual and onto other family members. In addition, pa } \\
\text { using drugs and not seeking help (due to stigma) are likel } \\
\text { contribute to the spread of infectious disease within the fa } \\
\text { affecting further on health, social, and economic survival } \\
\text { family unit. }\end{array}$ \\
\hline $\begin{array}{l}\text { Defense for } \\
\text { Children } \\
\text { International. } \\
\text { Palestine Section }\end{array}$ & $\begin{array}{l}\text { Attitudes of Educational } \\
\text { Counselors on Child } \\
\text { Abuse: A Field Study in } \\
\text { Palestinian National } \\
\text { Authority Schools (2006) }\end{array}$ & Arabic & $\begin{array}{l}\text { Cross sectional mixed } \\
\text { methods approach } \\
\text { including interview } \\
\text { and survey. } 742 \\
\text { Palestinian students } \\
\text { and } 35 \text { educational } \\
\text { counselors/teachers in } \\
\text { public schools }\end{array}$ & $\begin{array}{l}\text { This study reported that around } \\
90 \% \text { of counselors stated that } \\
\text { addicted parents assault their } \\
\text { children leading to behavioral } \\
\text { problems including the risk of } \\
\text { becoming addicts themselves or } \\
\text { developing weak personalities. }\end{array}$ & $\begin{array}{l}\text { Most educators reported the prevalence of physical and } \\
\text { emotional abuse of children of addicted parents. The risk } \\
\text { harm increases when a child lives within an addicted } \\
\text { household. Risks include physical, emotional and sexual. } \\
\text { Children risk psychical injury, addiction themselves, or b } \\
\text { sold into the sex trade. }\end{array}$ \\
\hline $\begin{array}{l}\text { Palestinian } \\
\text { National Institute } \\
\text { of Public Health, }\end{array}$ & $\begin{array}{l}\text { Illicit drug use in } \\
\text { Palestine: A qualitative } \\
\text { investigation (2017) }\end{array}$ & English & $\begin{array}{l}\text { As part of a larger } \\
\text { quantitative study, this } \\
\text { qualitative study }\end{array}$ & $\begin{array}{l}\text { This study found that children } \\
\text { and young people start to use } \\
\text { drugs at various ages and }\end{array}$ & $\begin{array}{l}\text { When a parent in the family uses drugs, an increased risk } \\
\text { their children will use drugs is noted. In addition to this, } \\
\text { children of drug users are at a risk of abuse, economic }\end{array}$ \\
\hline
\end{tabular}




\begin{tabular}{|c|c|c|c|c|c|}
\hline $\begin{array}{l}\text { Ministry of Health, } \\
\text { UNODC/KOICA/ } \\
\text { WHO occupied } \\
\text { Palestinian } \\
\text { Territory }\end{array}$ & & & $\begin{array}{l}\text { included } 13 \text { focus } \\
\text { groups and } 52 \\
\text { interviews with people } \\
\text { who used (currently } \\
\text { and previous) drugs } \\
\text { and their families in } \\
\text { both the West Bank } \\
\text { and Gaza. }\end{array}$ & $\begin{array}{l}\text { places, including the family } \\
\text { home, when other family } \\
\text { members use drugs. The most } \\
\text { likely group of people to start to } \\
\text { use drugs are children of drug } \\
\text { users. }\end{array}$ & $\begin{array}{l}\text { challenges, breakdown of relationships and social stigma } \\
\text { among the community. Sexual and physical abuse is also } \\
\text { and as a result, children of drug users (usually girls) run a } \\
\text { from drug using fathers for their own protection. }\end{array}$ \\
\hline $\begin{array}{l}\text { Damiri, B R, } \\
\text { Salahat, I A, and } \\
\text { Aghbar M H }\end{array}$ & $\begin{array}{l}\text { Pattern of substance use } \\
\text { among } \\
\text { schoolchildren in } \\
\text { Palestine: a cross- } \\
\text { sectional } \\
\text { study (2018) }\end{array}$ & English & $\begin{array}{l}\text { Cross-sectional study } \\
\text { of } 870 \text { children } \\
\text { sampled from across } \\
16 \text { schools in the West } \\
\text { Bank, of which } 828 \\
\text { completed a modified } \\
\text { version of the } \\
\text { Monitoring the Future } \\
\text { Study questionnaire }\end{array}$ & $\begin{array}{l}\text { The study found that where } \\
\text { there are substances used in the } \\
\text { family (alcohol, tobacco, and } \\
\text { drugs), children have greater } \\
\text { access to these substances and } \\
\text { thus have a greater risk of } \\
\text { addiction themselves. }\end{array}$ & $\begin{array}{l}\text { Where there is access to drugs, and an increased vulnerab } \\
\text { (i.e. child of drug users), children risk addiction themselv } \\
\text { Addiction has a range of health, social, and economic } \\
\text { consequences, but the additional factor that the addict is a } \\
\text { child means they are also exposed to sexual exploitation }\end{array}$ \\
\hline Shani, A & $\begin{array}{l}\text { Gaza kids live in hell: A } \\
\text { psychologist tells of } \\
\text { rampant sexual abuse, } \\
\text { drugs and despair (2017) }\end{array}$ & English & $\begin{array}{l}\text { Media interview with } \\
\text { Palestinian } \\
\text { psychologist }\end{array}$ & $\begin{array}{l}\text { The psychologist reports how } \\
\text { the Gaza strip is a place of } \\
\text { despair with increased reports of } \\
\text { child sexual abuse. The } \\
\text { interviewee notes that the } \\
\text { poverty and trauma families } \\
\text { experience are ignored or at } \\
\text { least silenced by professionals }\end{array}$ & $\begin{array}{l}\text { The addiction of a parent or a family member increases th } \\
\text { likelihood children becoming a target for sexual abuse or } \\
\text { indeed, it contributes to harmful sexual behaviors in child } \\
\text { who sexually abuse other children. }\end{array}$ \\
\hline
\end{tabular}


Conflict of Interest: The authors declare that they have no conflict of interest.

Manuscript Title: Palestinian children's experiences of drug abuse in the home in the Occupied Territories of Palestine: A scoping review of extant literature

\section{Authors:}

Marie Claire Van Hout, Professor, Public Health Institute (PHI), Liverpool John Moores University, Liverpool, United Kingdom

Mohammed Fathi Al-Afifi, Director, Substance Abuse Research Centre (SARC), Gaza Strip

Leen Abushams, Researcher, School of Pharmacy, University of Jordan, Amman, Jordan.

Stephanie Kewley, Senior Lecturer Forensic Psychology, School of Science, Liverpool John Moores University, Liverpool, United Kingdom.

Zara Quigg, Reader of Behavioural Epidemiology, Public Health Institute (PHI), Liverpool John Moores University, Liverpool, United Kingdom

Mark Whitfield, Intelligence and Surveillance Manager, Public Health Institute (PHI), Liverpool John Moores University, Liverpool, United Kingdom.

Jim McVeigh, Director, Public Health Institute (PHI), Liverpool John Moores University, Liverpool, United Kingdom

Mayyada Wazaify, PhD, Professor of Pharmacy, Department of Biopharmaceutics and Clinical Pharmacy, School of Pharmacy, The University of Jordan (UJ), Amman, Jordan 